\title{
Enhancing The Mechanical Properties of Montmorillonite-Filled Natural Rubber Through The Utilizing of Alkanolamide
}

\author{
$1^{\text {st }}$ A Warsita ${ }^{1}, 2^{\text {nd }}$ I Surya ${ }^{2}$ \\ indradanas@yahoo.com ${ }^{1}$, isurya@usu.ac.id ${ }^{2}$
}

\author{
Department of Mechanical Engineering, Sekolah Tinggi Teknologi Nasional \\ Yogyakarta, Depok, Sleman, Yogyakarta, Indonesia \\ Department of Chemical Engineering, Universitas Sumatera Utara, Medan, Indonesia
}

\begin{abstract}
The purpose of this article is to demonstrate how alkanolamide may improve the reinforcing effectiveness of montmorillonite on natural rubber (NR) compounds by including it into the formulation. The alkanolamide was synthesized in the laboratory and then added to the montmorillonite-filled NR compounds at intervals of $1,3,5$, and $7 \mathrm{phr}$, respectively. Researchers discovered that alkanolamide has modulus, hardness, and tensile strength improvements when compared to other compounds. The tensile modulus at 100 percent, as well as the hardness and tensile strength, were all improved, particularly up to a five percent alkanolamide concentration in the sample. As a result of using alkanolamide as a curative and plasticizing agent, it was discovered that the modulus and tensile enhancements were due to an increase in the reinforcing efficiency of montmorillonite on the NR. This was accomplished by increasing the degree of montmorillonite dispersion, the number of NR to montmorillonite interactions, and the cure state. According to the results of the crosslinks density test, it was determined that the montmorillonite-filled vulcanizate containing five percent alkanolamide had the highest crosslinks degree, resulting in the maximum hardness, tensile modulus, and tensile strength characteristics.
\end{abstract}

Keywords: Montmorillonite-Filled, Natural Rubber, Alkanolamide.

\section{Introduction}

Natural rubber (NR) is a widely used base rubber that is extremely well-known. Before vulcanization, it lacks a number of mechanical characteristics that are helpful. However, vulcanization transforms the weak, tacky, and less elastic base NR into a strong, non-tacky, and elastic NR vulcanizate by removing the tacky component. The filler reinforcement of empty NR vulcanizates may further improve the mechanical characteristics of the vulcanizates, resulting in improved overall performance.

In rubber vulcanizates, filler reinforcement is the process of improving the mechanical characteristics of the rubber by incorporating a reinforcing filler into the rubber mixture while it is still being formed. Silicas and carbon blacks (CBs) are well-known reinforcing fillers in the rubber industry for their strength and durability. Montmorillonite is also a kind of reinforcing Filler that may be used to increase the strength of rubber composites by increasing the amount 
of rubber utilized. A wide range of particle sizes, including nano-sized particles, are available for use in this product. Agglomeration of montmorillonite particles occurs when the particles of the mineral are brought together during the compounding process, in the same way as silicas and $\mathrm{CBs}$ do. Each of these montmorillonite agglomerations is made up of a unique combination of minerals. Rubber vulcanizates' mechanical qualities may deteriorate as a result of this [2]. When dealing with filler agglomerations, it is common practice to introduce a particular chemical as a dispersant/processing aid into the rubber compounds in order to solve the issue.

It is important to note that when utilizing montmorillonite as filler reinforcement in NR, the amount of filler reinforcement provided by montmorillonite is dependent on the establishment of stronger interactions between NR and montmorillonite. Those interactions are dependent on the surface area of the montmorillonite particles [3], and the montmorillonite agglomerations decrease the amount of accessible surface area of the montmorillonite that may interact with NR in a favorable manner.

The degree of reinforcement provided by montmorillonite may be measured by the effectiveness with which it reinforces [4]. In terms of reinforcing efficiency, this means that there are many interactions between NR and the montmorillonite, which are influenced by the degree of montmorillonite dispersion. Larger interactions between NR and montmorillonite may be achieved by dispersing the montmorillonite to a greater extent. Because of this, this research sought to improve the reinforcing effectiveness of montmorillonite on NR by adding alkanolamide into the mix.

\section{Chemicals and method}

\subsection{Chemicals}

The rubber lab at the USM Engineering Campus in Nibong Tebal, Malaysia, produced the NR as well as other rubber compounds such as sulfur, zinc oxide, nanosized montmorillonite, isopropyl-N'-phenyl-p-phenylenediamine, mercapto benzothiazolyl disulfide, and stearic acid. The alkanolamide was synthesized in the laboratory by reacting ethanolamine with RBDPS (tristearin).

\subsection{Compounding of NR}

In accordance with the semi-EV vulcanization system, the natural rubber (NR) and other rubber chemicals were combined. Sequences of NR compounding were performed on a lab-type 2-roll mill in accordance with ASTM D3184-80. The formula for NR compounding is shown in Table 1 below.

Table 1. The recipe for NR compounding

\begin{tabular}{ll}
\hline NR and chemicals & Content (phr.) \\
\hline NR & 100 \\
Sulfur & 1.5 \\
Isopropyl-N'-phenyl-p-phenylenediamine & 2 \\
Stearic acid & 2 \\
Mercapto benzothiazolyl disulfide & 1.5 \\
Zinc oxide & 5 \\
Montmorillonite & 8 \\
Alkanolamide & $0 ; 1 ; 3 ; 5 ;$ and 7 \\
\hline
\end{tabular}




\subsection{Optimum cure time and torque properties}

With the aid of a Rheometer, the optimal cure time (t90) and torque characteristics, which comprise maximum torque $(\mathrm{Mx})$, minimum torque $(\mathrm{Mn})$, and change in torque $(\mathrm{Mx}-\mathrm{Mn})$, were calculated in accordance with ISO 3417 and were tested (MDR 2000). The temperature at which the vulcanization took place was 150 degrees Celsius.

Calculation of the crosslink density in 2.42 .4

Swelling tests on NR compounds were carried out in toluene in accordance with ISO 1817 in order to determine the density of crosslinks in the compounds. Testing was performed on the vulcanized test materials, which were weighed using a scale and swelled in toluene until they reached equilibrium ( 72 hours, room temperature). To weigh the samples, they were withdrawn from the toluene and the toluene was washed away from the sample surfaces. The weight of the samples was determined. The samples were dried in an oven at 60 degrees Celsius until their weights remained consistent. Following the use of the Flory-Rehner Equation [5, the swelling findings were utilized to determine the molecular weight difference (Mc) between two crosslinks.

$$
\begin{gathered}
M_{c}=\frac{-\rho_{p} V_{s} V_{r}^{1 / 3}}{\ln \left(1-V_{r}\right)+V_{r}+\chi V_{r}^{2}} \\
V_{r}=\frac{1}{1+Q_{m}}
\end{gathered}
$$

NR density $(0.92 \mathrm{~g} / \mathrm{cm} 3)$, toluene molar volume $(106.4 \mathrm{~cm} 3 / \mathrm{mol})$, volume fraction of the $\mathrm{NR}$ in the swollen specimen $(\mathrm{Vr})$, weight increase $(\mathrm{Qm})$ of NR samples in toluene, and interaction parameter $(\mathrm{NR}=0.393)$ of the NR network-solvent are all given by the equations above. The degree of crosslink density is expressed as;

$$
V_{c}=\frac{1}{2 M_{c}}
$$

\subsection{Determination of mechanical properties and reinforcement efficiency}

According to ASTM D-882, the tensile modulus (M100) and tensile strength (TS) of vulcanized natural rubber (NR) were measured using a tensometer with an extension rate of 500 $\mathrm{mm} /$ minute.

With the use of a Shore A type Durometer, the hardness characteristics of the vulcanized NR were measured in accordance with ASTM D2240-05.

Equation 4 [4] was used to determine the reinforcement efficiency (RE) of the vulcanized NR based on the torque characteristics of the material.

$$
\operatorname{RE}(\%)=100 \%\left[(\mathrm{Mx}-\mathrm{Mn})_{\mathrm{f}}-(\mathrm{Mx}-\mathrm{Mn}) \mathrm{uf}\right] /(\mathrm{Mx}-\mathrm{Mn})_{\mathrm{uf}}
$$

In which;

$(\mathrm{Mx}-\mathrm{Mn})_{\mathrm{f}}=$ Torque change of filled NR vulcanizate; $(\mathrm{Mx}-\mathrm{Mn})_{\mathrm{uf}}=$ Torque change of unfilled NR vulcanizate. 


\section{Results and discussion}

\subsection{The optimum cure times and properties of torques}

Table 2 shows the effects of alkanolamide concentrations on the vulcanization characteristics of montmorillonite-filled NR, such as the optimal cure periods or $\mathrm{t} 90$, as well as the torque properties. According to the results given, the addition of one phr of alkanolamide shortened the optimal curing time of the NR control compound significantly. As a result, it was discovered that the addition alkanolamide served as a curative component by altering the vulcanization characteristics of the $\mathrm{N}$-nitroso compound. It is possible that the amine substance of alkanolamide has functioned as an additional accelerator, thereby improving performance of the principal accelerator or MBTS during the process of sulfurization. Because the nitrogen atom is a type of accelerator [6], decreasing the optimum cure time and increasing the velocity of sulfurization process are equivalent effects $[7,8]$. As alkanolamide concentrations increased, the optimal cure time was shortened even more. It was because of the more substantial love for acceleration that this occurred.

In accordance with Table 2, the addition of one phr of alkanolamide decreased the minimum torque (Mn). Because the minimum torque is correlated to the viscosity of the NR compound, the reductions in minimum torque or viscosity were caused by the oily characteristics of alkanolamide, which reduced viscosity, respectively. Oils and oily materials, according to theory, have the ability to act as plasticizing agents.

Viscosity was reduced due to an increase in the concentration of alkanolamides in the water solution. It was caused by the alkanolamide's increased plasticizing activity, which was more pronounced.

Table 2. The influences of alkanolamide on the t90 and torques properties of NR

\begin{tabular}{lrrrrr}
\hline NR & \multicolumn{5}{c}{ Alkanolamide (phr) } \\
\cline { 2 - 6 } compounds & 0.0 & 1.0 & 3.0 & 5.0 & 7.0 \\
\hline t90, minutes & 5.0 & 4.9 & 4.5 & 3.9 & 3.2 \\
Mx, dN.m & 5.91 & 6.07 & 6.74 & 6.96 & 6.70 \\
Mn, dN.m & 0.06 & 0.05 & 0.04 & 0.03 & 0.02 \\
Mx-Mn, dN.m & 5.85 & 6.02 & 6.70 & 6.93 & 6.68 \\
\hline
\end{tabular}

As seen in Table 2, the addition of one phr of alkanolamide increased the maximum torque, denoted by the letter Mx. Because maximum torque demonstrates the stock modulus, the increase in maximum torque was attributable to the alkanolamide's role as a compatibilizing agent, which enhanced both the intercalation and exfoliation processes in the amorphous phase. The rise in maximum torque, as well as the intercalation and exfoliation processes, became increasingly substantial when the alkanolamide concentrations were raised to a maximum of five phr, and this trend continued.

\subsection{Filler dispersion properties}

The torques properties of NR compounds determined the montmorillonite dispersion degree inside the NR compounds by using Equation (5) [7].

$$
\mathrm{L}=\eta_{\mathrm{R}}-\mathrm{m}_{\mathrm{R}}
$$

In this equation, $\mathrm{R}$ equals [Mn $\mathrm{f} / \mathrm{Mn} \mathrm{g}$ ], and $\mathrm{Mx}$ f equals [Mx g], where $\mathrm{Mn} \mathrm{f}$ and $\mathrm{Mx} \mathrm{f}$ were the minimum and maximum torques of the filled $\mathrm{NR}$, while $\mathrm{Mx} g$ and $\mathrm{Mx}$ gr were the minimum and maximum torques of the gum/unfilled NR, respectively. At a given montmorillonite concentration, a greater $\mathrm{L}$ value indicates a lower quality.degree of The dispersion of 
montmorillonite. In the case of gum NR, the lowest and maximum torques were 0.72 and 6.18 , respectively [8].

As shown in Fig. 1, the $\mathrm{L}$ values at different alkanolamide concentrations are shown against time. As seen in the graph, the $\mathrm{L}$ values of NR systems including alkanolamide were lower when compared to the $\mathrm{L}$ values of filled NR systems with no alkanolamide. The increasing concentration of alkanolamide resulted in a decrease in the $\mathrm{L}$ value. It was owing to the plasticizing properties of alkanolamide that the viscosity was reduced and the montmorillonite dispersion degree was improved, respectively, in this experiment.

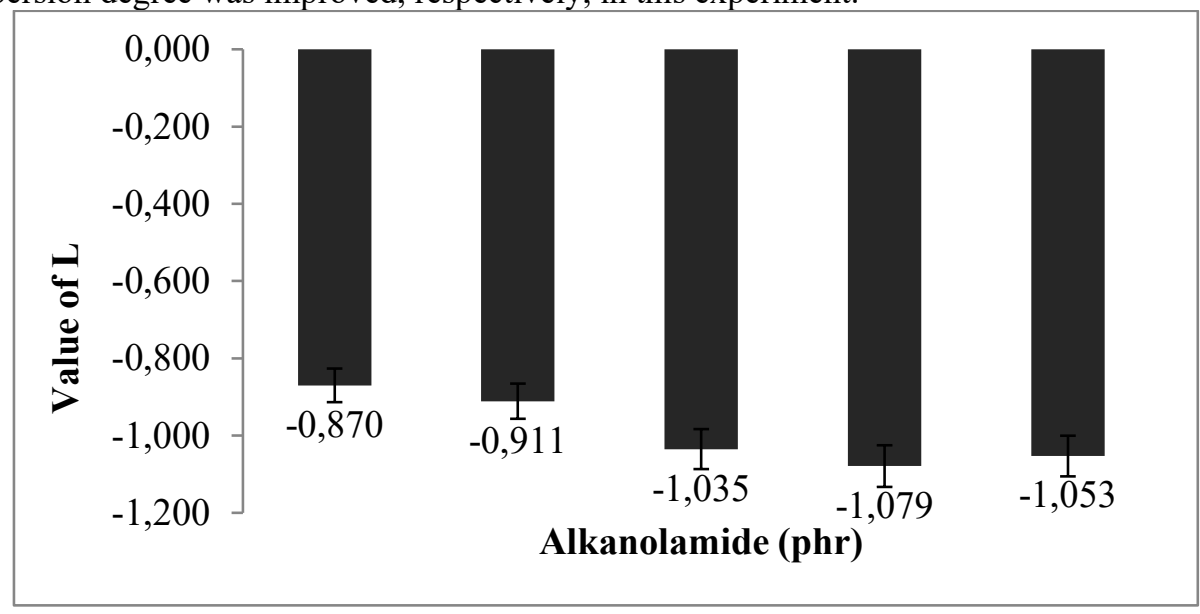

Fig. 1. The value of $L$ vs alkanolamide concentration

\subsection{Crosslinks density}

The effects of alkanolamide concentrations on the density of crosslinks in montmorillonitefilled NR are shown in Fig. 2. As can be observed, the addition of one phr of alkanolamide resulted in a significant increase of crosslinks. Crosslinks were further enhanced by increasing the alkanolamide concentrations up to a five-fold increase in time. Attributable to the fact that total crosslinks in a rubber vulcanizate are the sum of physical and sulphide crosslinks, the increase in crosslinks was due to an improvement in physical crosslinks as a result of the activity of alkanolamide as a compatibilizing agent.

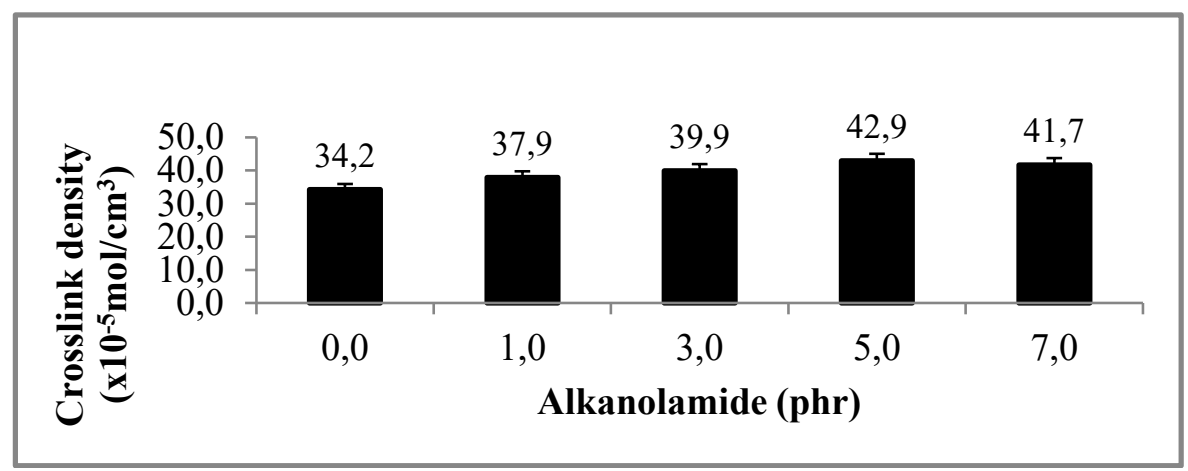

Fig. 2. The crosslinks density vs alkanolamide concentration 


\subsection{Reinforcement efficiency (RE)}

The reinforcing efficiency, abbreviated RE, is shown in Fig. 3. NR filled with montmorillonite and tested for tensile strength (TS) in the presence of alkanolamide is shown in Table 3 as M100, hardness, and tensile strength (TS). Figure 3 and Table 3 show that adding one phr of alkanolamide to the NR control compound increased the RE, M100, hardness, and TS of the NR control compound significantly. The improvement in NR crosslinks as a result of improving the NR to montmorillonite interactions or physical crosslinks [9-12] was responsible for the increase in RE and mechanical characteristics [9-12].

The increasing of alkanolamide concentrations up to a five-phr level further improved the RE and mechanical characteristics; but, beyond the five-phr level of alkanolamide concentration, the RE and mechanical properties began to deteriorate significantly. The improvement in crosslinks was responsible for the increase in mechanical characteristics, while the deterioration in mechanical properties was caused by the decrease in crosslinks (see Figure $1)$.

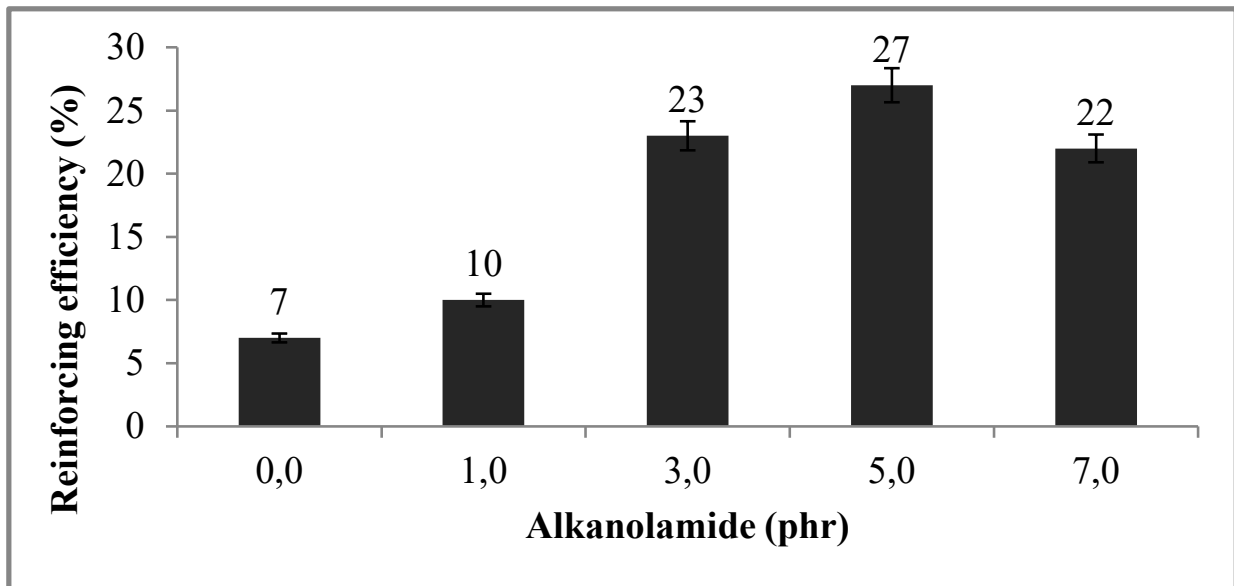

Fig. 3. The reinforcing efficiency vs alkanolamide concentration

Table 3. The mechanical properties of NR vulcanizates

\begin{tabular}{lrrrrr}
\hline NR & \multicolumn{5}{c}{ Alkanolamide (phr) } \\
\cline { 2 - 6 } vulcanizates & 0.0 & 1.0 & 3.0 & 5.0 & 7.0 \\
\hline M100, Mega Pascal & 0.65 & 0.70 & 0.79 & 0.82 & 0.81 \\
TS, Mega Pascal & 19.4 & 19.9 & 20.5 & 24.9 & 21.7 \\
Hardness, Shore A & 40 & 43 & 44 & 45 & 44 \\
\hline
\end{tabular}

\section{Conclusion}

The alkanolamide enhanced the reinforcing efficiency of montmorillonite on natural rubber compounds. The reinforcing efficiency was enhanced by improving the degree of montmorillonite dispersion and natural rubber to montmorillonite interactions, respectively. The enhancing in mechanical properties was due to the enhancing in crosslinks as well as the cure state. The crosslink density test confirmed that the five phr of alkanolamide was the optimum concentration for montmorillonite-filled natural rubber compounds which yielded the highest hardness, tensile modulus and tensile strength. 
On natural rubber compounds, the alkanolamide increased the effectiveness of montmorillonite as a reinforcing agent. The degree of montmorillonite dispersion and the degree of natural rubber to montmorillonite interactions were improved in order to increase the reinforcing efficiency. Increasing the number of crosslinks in the material as well as the cure condition contributed to the improvement in mechanical characteristics. Crosslink density testing showed that five percent by weight of alkanolamide was the optimal concentration for montmorillonite-filled natural rubber composites, with the greatest hardness, tensile modulus, and tensile strength being obtained.

\section{Acknowledgement.}

The authors thank the rubber lab of Engineering Campus of Universiti Sains Malaysia, Nibong Tebal, Malaysia for the availability of research facilities.

\section{References}

[1] Surya I and Ginting M 2019 J Phys Conf Ser 1373012023.

[2] Surya I and Ismail H 2019 IOP Conf Ser Mater Sci Eng 509012053.

[3] Boonstra B B 1973 Polymer 20 (6) 691-704.

[4] Hashim A S, Kohjiya S and Ikeda Y 1995 Polym Int 38 (2) 111-117.

[5] Flory P J and Rehner J Jr 1943 J Chem Phys 11521.

[6] Rodgers B 2004 Rubber Compounding: Chemistry and Applications CRC.

[7] Lee B 1979 Rubber Chem Technol 52 (9) 1019-29.

[8] Surya I, Ismail H and Azura A R 2015 Polym Test 42 208-14.

[9] Sianturi R W and Surya I 2018 J Phys Conf Ser 1116 (4) 042033.

[10] Surya I, Hayeemasae N and Ginting M 2018 IOP Conf Ser Mater Sci Eng 343012009.

[11] Andriani F and Surya I 2018 J Phys Conf Ser 1116 (4) 042005.

[12] Surya I, Ginting M and Anto J 2018 AIP Conf Proc 2024 (1) 020061. 